\title{
Chinese Tourists and Confucianism
}

\begin{abstract}
Anna Kwek
PhD Candidate

Griffith Business School

Department of Tourism, Leisure,

Hotel and Sport Management

Gold Coast Campus,

Griffith University

PMB 50, Gold Coast Mail Centre

Queensland 9726
\end{abstract}

Australia

Tel: 61(07) 55529231

Fax: 61(07) 55528507

Email Address:

A.Kwek@griffith.edu.au
Dr Young-Sook Lee

Lecturer

Griffith Business School

Department of Tourism, Leisure, Hotel and Sport Management

Gold Coast Campus,

Griffith University

PMB 50, Gold Coast Mail Centre

Queensland 9726

Australia

Tel: 61(07) 55528142

Fax: 61(07) 55528507

Email Address:

Young-Sook.Lee@griffith.edu.au 


\begin{abstract}
Despite the widespread belief on the significance of Confucianism upon the behaviour of Mainland Chinese people, limited empirical studies have been conducted to examine the Chinese cultural and philosophical ideology in a tourism context. As an exploratory attempt, this paper investigates the influence of Confucian values on Mainland Chinese corporate travellers at leisure on the Gold Coast, Australia. Based on participant observations of group package tours, this paper suggests that the notion of harmony dominates and underlines the Chinese tourists' behaviour as tourists. The notion of harmony, further, was intricately related with such themes as respect for authority, relationship building or Guanxi and conformity. Heavily influenced by the values of Confucianism, the travellers placed much emphasis on maintaining not only the correct and appropriate behaviour, which included paying due respect to one’s superior, but also practicing forbearance conforming to the interests of a wider group rather than individual desires. Relationship building appears to be a salient motivation, underlying the behaviours of the tourists. Confirming the suggestions from other disciplinary fields, such as Chinese psychology and social psychology, this paper highlights the need for more research attempts in this area for practical and theoretical advancements in our understandings.
\end{abstract}

Keywords: Confucianism, Chinese corporate leisure travellers 


\section{Introduction}

It is widely viewed that culture influences people's behaviour (Hofstede, 1980) and Chinese people are believed to be strongly influenced by the teachings of Confucius (551-479 BC). This exploratory research investigates the 'assumed' influence of Confucianism on Chinese people in a tourism context. Specifically, we are interested in the dynamics of corporate/leisure groups of Mainland Chinese on the Gold Coast, Australia. We identify main themes representing the tourists' behaviour through participant observation and interviews. We then look into the nature of the identified themes and seek their links to Confucius values. Overall aim of this study is to determine how important role Confucianism may play in the Chinese tourism setting.

As this study setting is Mainland Chinese corporate/ leisure group tourists, we also direct our attention to the research on group package tours. The phenomenon of group travel in tourism is a relatively under-researched topic with only a handful of articles published in academic journals (Bowen, 2002; Crompton, 1981; Fairley, 2003; Holloway, 1981; Quiroga, 1990; Schmidt, 1979; Schuchat, 1983; Tucker, 2005). Due to various factors such as language barriers, safety reasons and ease of travel many tourists from China, Taiwan, Korea, Japan and Hong Kong choose group package tour as the main modes of outbound travel. Fuelled by the economic growth in recent years, tourists from South-East Asia, especially countries like Korea and China have seen tremendous increase in outbound travel, accentuating the demand for group package tours. Yet, a review of the literature indicates that both group package tour and Chinese outbound tourism are relatively under-researched topics. As Chinese outbound tourism market is relatively a new market, tourism studies on Chinese tourists are also limited. By 
investigating the influences of the Chinese cultural and philosophical value of Confucianism on the new tourists market, this paper can contribute to better understanding the Chinese tourists market from a cultural perspective.

\section{Confucianism and Chinese Cultural Values}

The influence of cultural values on behaviour is well documented (Goffman, 1959; Hofstede, 1980; Hofstede and Hofstede, 2005). As a core of Chinese culture, Confucianism is still very much alive in today's Chinese societies. The fundamental principles of Confucianism are grounded in the observance of the five virtues (also known as the 'Five Constant Regulations') namely, Ren (love and benevolence), Yi (righteousness), $\mathrm{Li}$ (propriety or rites), Zhi (wisdom) and Xin (sincerity or trustworthiness) (Chan, Ko, \& Yu, 2000; Lu, 1983; Tamney \& Chiang, 2002; Yao, 2000).

These virtues constitute the basis of moral order and values and are interrelated with each other. While Ren is signified as the most fundamental and central idea of Confucian philosophy, which connotes human acts such as "tolerance, forgiveness, deference, filial obedience (to parents), faithfulness (to master), wisdom, honesty....” (Lu, 1983, p.29), Yi signifies rightness that exists in man's relationship with his friends. $\mathrm{Li}$ is the moral force, which governs correct and appropriate behaviour and man's relationship with each other and reflected through personal loyalty. Xin represents not only the sincerity and trustworthiness of a person but also the credibility of his words and actions. Zhi is the wisdom and knowledge needed for self-cultivation. Through Zhi, the doctrines of Ren, Li, Xin and Yi can thus be practiced and enacted (Tamney \& Chiang, 2002). 
Through self-cultivation, fulfilment of these virtues is reflected through the ‘Three Guiding Principles’ in the following relationships: (1) sovereign and subjects, (2) father and son, (3) husband and wife (Yao, 2000; Yau, 2000). The self is presented as part of human relationship whereby every individual is burdened by his or her obligations in each relationship. Each relationship will in turn add to the growth and structure of the self (Tu, 1984). This interrelationship among individuals of a society ultimately forms the social and political structure of the state (Tamney \& Chiang, 2002; Yao, 2000).

Another distinctive trait in the Chinese culture is the 'face' concept. There is a growing literature that addresses this concept (Gong, 2002; Tai \& Tam, 1996; Yau \& Steele, 2000). This is a concept of great importance in the interpersonal relations among Chinese (Yau, 1994). This concept has two dimensions: ‘lien’ and ‘mien-tsu'. According to Hu (1944, cited in Yau, 1994), 'lien’ is the confidence and integrity of one’s moral character and ego, which the loss of 'lien’ would diminish his status and functionality in society, while 'mien-tsu', represents a person's achievement, success and prestige in life. 'Mien-tsu' is not only a function of a person's social status, but it also act as a barometer for one's conduct and performance. To better comprehend this concept, one must understand that the standard and requirements of these social behaviours are social expectations held by the group with whom one is interacting. In comparison, 'lien' is more important than 'mien-tsu' as “mien-tsu' can be regained more easily when one loses it. But the loss of 'lien' represents the loss of one's integrity of character and this, in Chinese culture, is a loss of a most fundamental requirement of being human, sometimes leading to suicides (Yau, 2000, p.142). The concept of face is a reflection of the social 
psychological processes in Chinese society that emphasises the importance placed on social status and expectations.

\section{Studies on Group Package Tours}

A review on relevant literature on group package tour reveals that majority of studies conducted so far are focused on three main aspects namely; (1) the tourism trends and development of Chinese outbound tourism (Cai, O'Leary, \& Boger, 1999; Davidson, Hertrich, \& Schwandner, 2004; Zhang, Pine, \& Zhang, 2000; Zhang, Chong, \& Ap, 1999; Zhang \& Heung, 2001; Zhang \& Qu, 1996), (2) Trip, travel and behavioural characteristics (Cai et al., 1999; Huang \& Hsu, 2005; Qu \& Li, 1997; Ryan \& Mo, 2001; Yoo, McKercher, \& Mena, 2004; Zhang \& Heung, 2001; Zhang \& Lam, 1999), and (3) tourist satisfaction, motivation and perception (Huang \& Hsu, 2005; Kau \& Lim, 2005; Ryan \& Mo, 2001; Zhang \& Lam, 1999). The potential and implications of this rising tourist market to destinations all over the world highlight the need for more research, for both academic and operational level advancements.

Tourism studies conducted on group travel or group package tour tend to pay more attention on topics such as (1) satisfaction and service quality (Bowie \& Chang, 2005; Quiroga, 1990; Wang, Hsieh, Chou, \& Lin, 2007; Wang, Hsieh, \& Huan, 2000), (2) role of the tour guide (Bowie \& Chang, 2005; Cohen, 1985; Holloway, 1981; Wang, Hsieh, \& Chen, 2002), (3) group processes (Crompton, 1981; Gorman, 1979; Quiroga, 1990) and, (4) the touring experience (Fairley, 2003; Tucker, 2005).

Quiroga (1990) examined two aspects of coach tours. The study explored the formation of groups in coach tours as well as the variables that influence customer 
satisfaction. Some of the variables that influence customer satisfaction were (1) positive group dynamics, (2) role of tour guide and, (3) exposure to cultural exchanges. Similarly, a study conducted by Bowie and Chang (2005) also found that the role of the tour guide is an important variable that influence customer satisfaction in package tour. In addition, customer expectations, attitudes and behaviour were also identified as factors affecting customer satisfaction and service delivery. Earlier, the role of the tour guide has been argued as one of the most significant determinant in the success of group tours (Holloway, 1981).

Fairley (2003) examined the experiences and motivations of a small group that travels annually to follow a football team to a competition in a different state. Nostalgia was identified as the main motive for travelling to follow the group that not only allowed the group to reminisce about past experiences but also reinforces the group’s identity. The experience of being on a package tour was conducted by Tucker (2005). The study explored the self-performance of tourists, aimed at understanding how tourists assign meaning and significance to their touring experience. The findings of the study suggested that young people participating in group tours view the touring experience as an opportunity to socialise and meet new people. The social aspects of this experience overshadow the importance of seeing new places while older people viewed the touring experience as a means to confirm their self-identity as well as to reaffirm their sense of nearing mortality.

As an early study in this area, Crompton (1981) investigated the significance of social groups in a tourism context. The study suggested that social group plays an important role in enhancing a vacation not only by reducing costs and loneliness, but also 
by providing other members with a ready audience and camaraderie to share this new experience with. This feeling/atmosphere of camaraderie and group solidarity was also observed in the studies of Crompton (1981) and Gorman (1979). Quiroga (1990) reported that tourists often suffer from travel disorientation; a symptom which encourages tour group members to band together to increase social interaction. Positive group dynamics often reduces personality and compatibility clashes among tour group members.

The review on the literature both on Chinese cultural values and group package tours leads to our two research questions:

$R Q 1$. What are the major themes that represent the behaviours of the Mainland Chinese corporate travellers at leisure on the Gold Coast, Australia? $R Q 2$. How are/is the identified theme/s reflecting Confucian values, if any?

\section{Method}

This paper adopts an interpretive research paradigm and an overt participant observation with interviews is the chosen method. Purposive sampling was used to identify cases, which were "particularly important in the scheme of things" (Patton, 2002. p.236) and displayed the utmost impact on the growth of understanding.

The target participants were Mainland Chinese (MC) nationals, visiting Australia on a corporate/leisure trip and have chosen the Gold Coast as the destination for their leisure segment. The research participants consisted of ten fully guided tours of sixty-four people, of which fifty-five of them were males and nine females. The smallest group had two members, while the largest group had twelve. Predominantly male-oriented, the age group of the tour members ranged from early thirties to mid sixties with most of them 
possessing tertiary education and holding middle to top management positions. The length of stay varied from one to three nights. These tour packages were usually programmed and sold by outbound agents in China, who would then contract these tour businesses to Australian inbound tour operators. As most these tour packages have multidestination itinerary, the appointed tour operator usually sub-contracts various segments of the itinerary to other tour operators in different cities. The Gold Coast was designated as the destination for "rest and relaxation" segment of their visit because of its image as a beach resort. Members of these tour packages came from professions, consisting mainly of (1) government officials on business travel, (2) private business personnel and, (3) incentive corporate travellers.

For this research, various tour groups were visited and the tour members were informed of the research purpose. Participating undisguised, observations were focused on the behaviours and activities engaged by tour members and discourses with the tourists were also undertaken throughout the day. Further, in-depth interviews were conducted with tour group members as and when they were possible. In general, these interviews were conducted at times such as (1) the time spent waiting for the coach to arrive, (2) the time spent waiting for other members of the group, (3) travelling time and (4) the time before, during and after a meal. Observing, listening and note-taking occurred simultaneously. Constant consultation with the tour guide was used as a form of member checking (Creswell \& Miller, 2000) to affirm and enhance the adequacy and accuracy of information.

The interviews and on-tour observations and notes were then transcribed. As most of the interviews and discourses were conducted in Mandarin, transcribed texts were 
translated into English before embarking on coding. Once the translation was completed, the texts were manually coded and analysed by thematic content analysis (Winter, 1992). The analysis looked for recurring themes, representing the behavioural patterns of the Chinese tourists.

\section{Findings}

Findings show that like many East Asians, Mainland Chinese people behave in a highly collectivistic framework in the tourism context. While this research is located within corporate travel context, it is obvious from the observations and interviews that members of the tour groups continue to operate at the corporate organisational level. Indeed, the tourists were conspicuously displaying values like conformity, respect for authority, and guanxi, which were all interrelated with one another. Conceptual framework of the research findings, in which the notion of harmony underpins the themes representing the tourists' behaviours, is presented in Figure 1. 


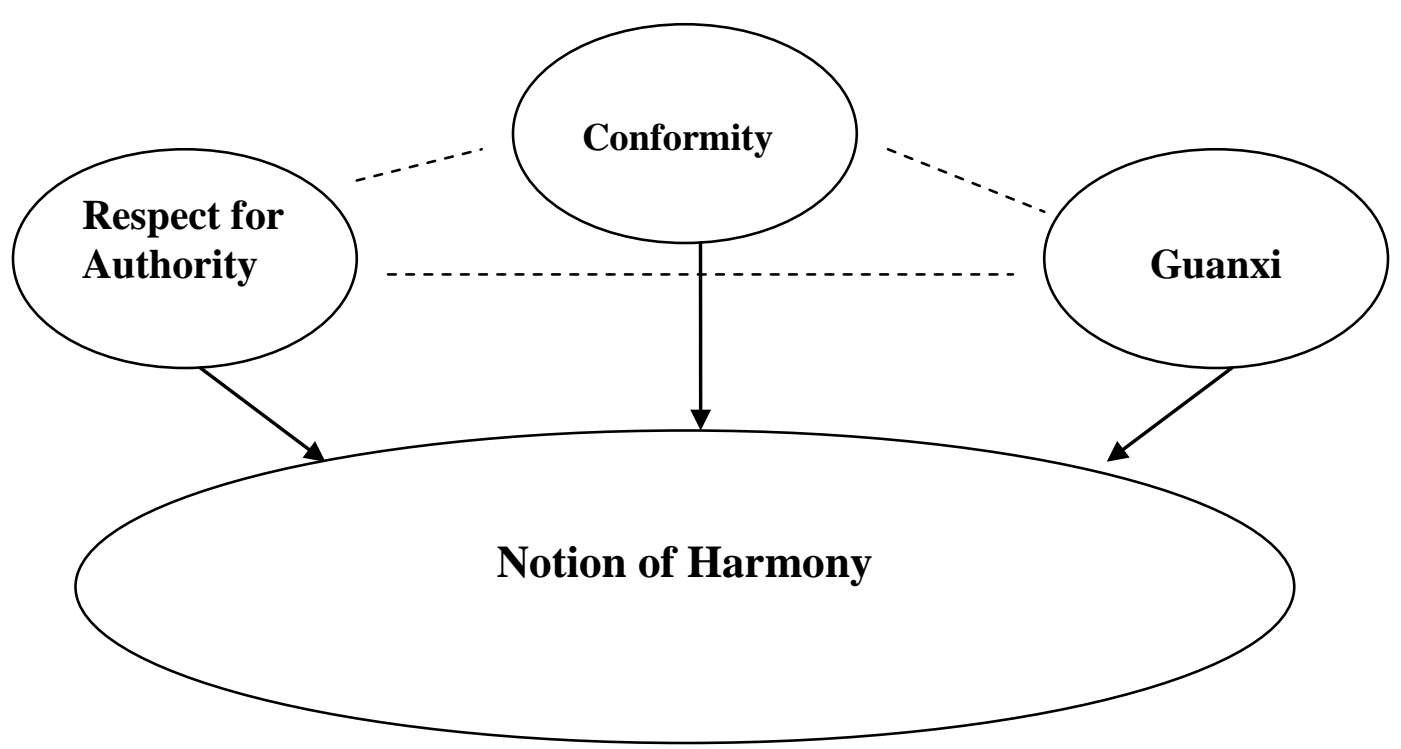

Figure 1. Emerged themes representing the Chinese tourists’ behaviour

\section{Respect for Authority}

In every MC corporate/leisure tour group observed, there was a 'leader' in each one. The leader of the group was usually the person who holds the highest social status in the group. This person could be the company's director, head of the department, a member of the Chinese Communist Party or even the person who is the most senior in age. Often, in order to uphold societal order, a rigid social structure is put in place, focussing on vertical relationships among people and respect for authority (Redding \& Wong, 1986). In order to achieve harmony, one may need to practice forbearance and the suppression of personal goals in the pursuit of harmonious relationships (Leung, Koch \& Lu, 2002). Chinese organisational leadership is often directive and authoritarian, demanding the submission of subordinates (Bond \& Hwang, 1986) and any open conflict would suggest 
disrespect for authority and challenge against the power of the superior (Tjosvold, Hui, \& Sun, 2004).

As an individual, the role he or she plays in a group is significant as the individual is expected to respect the vertical order or hierarchy. As such, members of the tour group would always look upon the leader for directions and all decisions as a symbol of protecting the social face of the leader. Whether it was choosing a restaurant for dinner, or what activities to do next, group members had the tendency to leave all the decisionmaking power to the leader. One group member from Shanghai commented:

We have only joined the company for a short time and as junior managers, we are still considered very inexperienced. When your position in the company is still quite junior, you are expected to respect and obey your seniors and leave all decisions to your leader. It would be most unthinkable for anyone to try and take precedence (male, early thirties, accountant).

The need to maintain positive interpersonal relationship between the leaders and subordinates was an exemplary of Confucian ideology. However, this could result in the suppression of personal preferences to conform to the interests of the leader and other group members. Members of a tour group from Nanjing remarked:

Even though we are not very interested in visiting the theme parks, we would still oblige and go with the group. We don't want to be seen as a deviant or going against the leader's decision (male, early forties, factory manager).

According to Silin (1976), some of the setbacks of Chinese vertical relationships are (1) overconcentration of power at the top, (2) leaving little or no room for subordinate initiatives and, (3) serious repercussions for the subordinate that do not conform to the 
leader's decisions. These findings are however, reflected in the behaviour demonstrated by members of the tour group through (1) refraining from making any decision, (2) leaving all decision-making to the leader and, (3) conforming to the decisions made by the leader.

As suggested in previous studies, some of the essential Chinese values such as hierarchy, authority, respect, loyalty and harmony is deeply embedded in each Chinese person, influencing individual's role and behaviour (Warner \& Zhu, 2002; Zhang, 1999). In other words, the underlying central idea to the observed respect for authority is the notion of harmony.

\section{Conformity}

Conflict avoidance has been argued to be widespread in Chinese societies and organisations, because open confrontations communicate disrespect and disrupt harmony (Bond \& Hwang, 1986). From the observations and interviewed, tourists' desire to maintain harmonious relationships by conforming to arbitrarily set rules of the group was apparent. In order to maintain harmony and avoid open conflicts, group members tend to conform, preferring to adopt a submissive role to the extent of suppressing individual preferences. In a Chinese society that emphasises on vertical relationships between superiors and subordinates and high power distance, it is important for subordinates not only to demonstrate obedience (Littrell, 2002), but also be able to appear “obliging” and not create any interpersonal disharmony.

As such, members of the various tour groups exhibited significant conformity among themselves. Conformity refers to situations whereby individuals are motivated to 
adhere to specific social behaviours and attitudes prevalent in that group (Baron \& Kerr, 2003). Conformity to group standards and norms is a distinct characteristic of group solidarity and a consequence of group pressure (Hogg, 1992). According to one guide:

MC tour groups tend to be quite cohesive. Doing things together not only give them a sense of security, but also allows us (the tour guides) to better manage the group. As most of them have very limited or no English, getting around on their own pose a significant problem.

Several members commented that the trip was made more meaningful because of the other group members. In particular, one member claimed:

These kinds of company trips are good opportunities for employees to get to know each other better. Especially when the company is relatively large with many offices all over China, this is a really good opportunity to meet those who work in other cities. The interaction among the group lifts up the mood, everyone is joking and laughing, it’s a good feeling (male, early forties, office manager, Dalian).

At the theme parks, everyone moved around together and participated in the activities as a group. From the observations, it would seem that members cherished the opportunity to share the experience and the bigger the group size, the more willing group members were to participate in thrill rides with other members; while groups with smaller number of participants were more reserved. No members observed so far have suggested going their own way, as that would be seen as an act of trying to deviate from the group.

Throughout the fieldwork process, the importance of these cultural values were constantly enacted and reflected in the desire of tour members to conform to the wider interests of the group. As reflected in our findings, some of the reasons for participating 
in group activities and caring for each other were because they were in a foreign land and could not speak the language. While majority of the tour members have travelled overseas prior to this trip, however, many of those trips were also tour packages to destinations in South East Asia where Mandarin is spoken widely. Due to their lack of knowledge of Western culture and communication skills in the English language, a high degree of dependence and reliance on the tour guide as well as other group members is inevitable. Furthermore, according to one member:

When you are representing your department in corporate trips like this, you need to be more obliging and show more consideration for others. Those who are not willing to conform to the interests of the wider group are often deemed selfish, arrogant and disrespectful (female, mid forties, Beijing).

As observed, the quintessential motivation for the individuals to conform is related to the notion of harmony in this Chinese group tour setting on the Gold Coast.

\section{Guanxi}

From the field observations, it was obvious that intragroup interactions were focused not only on establishing and building new relationships but also on further developing existing relationships. The practice of Chinese relationship building or guanxi is one of the most significant features of Chinese culture and a critical tool when doing business in China (Buttery \& Wong, 1999; Wong \& Chan, 1999; Wong \& Tam, 2000). Guanxi has been defined as the existence of direct particularistic ties between two or more people in which these ties determine the strength and closeness of the relationship (Jacobs, 1979). This relationship is also built on the foundation of implicit exchange of favours and a 
commitment to others by a silent code of reciprocity and equity (Luo, 1997). This is also supported by Peng (1997), who argued that a successful social and business relationships between people and organisation must possess clearly defined "mutual obligations, assurances and understanding” (p.448).

Social networking activities are common and routine part of corporate working life. Deeply rooted in the culture of the Chinese people, social networking activities are critical and crucial mechanisms that enable the development of relationship building. Activities like lavish banquets and gift giving are common and regular among Chinese business relationships (Szeto \& Wright, 2006). This aspect of the Chinese culture could also be evidenced among the observed business and leisure tour groups. Dinners were lavish and extravagant affairs with the leaders ordering not only the most expensive menus available but also ordering excessive amount of food. Often, the level of wastage was quite appalling. Accompanying these lavish dinners were also the excessive amount of alcohol drinking. A member (male, early fifties, general manager) from Shanghai explained:

The Chinese people show their hospitality and sincerity by throwing a lavish banquet for their guests. Any less extravagant would indicate an unenthusiastic and lack of regard attitude for the guests and the relationships.

As such, one must prove his eagerness and sincerity to develop relationships with potential business associates through overgenerous banquets and a constant flow of liquor to ensure the success of business deals. The constant drink toasting that accompanies these dinners is also a reflection of individual's hospitality and sincerity to his guests. One member commented: 
Even if you really can't drink, you would still have to drink. Nobody would believe that you can't drink unless you prove it to them. You would then have to drink till you become sick and unable to drink any more. To flatly refuse to drink is a sign of not giving face to your hosts or guests and that is socially not acceptable. So, to show your sincerity, you have to drink. This is the way Chinese people do business (male, late thirties, marketing manager).

Another member from added:

If you tried to order from a cheaper menu, your guests would immediately be very unhappy as that is a sign of disregard and disrespect for the relationship. Dinner will end quickly because your guest would not want to waste his time on someone who has not given him any face (male, late forties, businessman, Xiamen).

As been observed, the tourists’ performing of guanxi as corporate group tourists may not be viewed as surprising. What comes out clear is that in order to build and maintain appropriate relationships, people were employing social strategies such as showing respect to the power of the group and meeting the group's expectations. This, then, shows the relatedness of the theme of guanxi to respect for authority and conformity, further extending to the notion of harmony.

\section{Notion of Harmony}

Reflecting on the observations from the fieldtrips, the notion of harmony emerged as the centrally underpinning concept across the three identified themes of respect for authority, conformity and Guanxi. Most of the members of the tour groups knew each other prior to the trip, either as work colleagues or through their line of business. The majority of them 
saw the trip not only as an opportunity to travel overseas but also to further develop existing relationships relating to the theme of Guanxi. The average tour itinerary to Australia is about eight to fourteen days, covering as many as seven cities, most of the travelling is spent onboard a coach. Because of the amount of time spent together as a group, constant interactions and communication among members become inevitable. When asked if they have encountered any differences in opinions, views and ideas among group members during the trip, one member from Shanghai put it this way:

You know, this is a business cum pleasure trip and it's paid for by the company. To able to travel overseas is such a rare opportunity! We've known each other for years, and unlikely to quarrel over petty things. Furthermore, when you are in a foreign land and cannot speak the language, we must look after each other. This outing is only successful when every member of this group goes home happy and satisfaction. So far, we have been a very co-operative group. We just let our Chairman (the boss of the company) lead the way (male, mid-forties, marketing manager).

Another member from Beijing commented:

Let me tell you this. We are honoured to be invited by our supplier to visit Australia. To organise a trip like this is not easy in China. It's our first visit to Australia and everyone here wants to make the most out of this opportunity. The Chinese people have for centuries, cultivated the habit to strive for harmony in every situation and as long as everyone is happy, we are also happy to oblige (male, early fifties, businessman, Beijing). 
Both statements reflect an underlying tendency to avoid conflicts and instead seek harmony even if it means that one has to endure and sacrifice for the sake of the whole group, which relate to the identified theme of conformity.

Throughout the tours, much emphasis was given in seeking harmony within the groups to (1) pleasing certain individuals in the group or showing 'respect for authority'; (2) group participation of touristic activities or demonstrating 'conformity'; and (3) establishing and/ or maintaining appropriate relationship, or Guanxi. Indeed, most of the tour participants were operating in their corporate organisational identity.

\section{Harmony and Confucianism value of ' $\mathrm{Li}$ '}

In a close inspection of the notion of harmony, which overall underpins the themes representing the tourists' behaviour, we can see the Confucianism value of ' $\mathrm{Li}$ ' is reflected. The concept of ' $L i$ ' is one of the fundamental principles of Confucianism and is seen as a guide to developing goodness in man through appropriate behavioural norms (Chai \& Chai, 1973). $\mathrm{Li}$ is the moral force, which governs correct and moral behaviour and man's relationship with each other. The ultimate importance in Confucianism is societal order and harmony, which emphasises the upholding of traditions and conducting oneself with propriety. Given the Chinese peoples’ pursuit of harmonious relationships with others, conflict avoidance naturally becomes a distinct feature in the social interaction of Chinese societies by conforming to group norms.

The Chinese concept of harmony connotes meanings such as peace, being of mild and gentle nature and having a good relationship with another, and the belief that "if the family lives in harmony, all affairs will prosper' (Leung et al., 2002). Given the 
collectivistic and hierarchical nature of Chinese interpersonal relationships, maintaining harmonious relationships promotes and protects social face as well as strengthens positive relationships, critical to doing business (Tjosvold et al., 2004). In our research findings, the Chinese tourists made efforts consciously and unconsciously, trying to display their respect for authority, show their earnestness by conforming to the interests of their groups and constantly 'worked' to develop and maintain appropriate relationships.

\section{Implications for industry and academia}

From this research we can draw implications for both industry and academia. For the industry sector, which deals with the Chinese inbound tourists, we would like to highlight the importance of Chinese cultural values highlighted by the industry practitioners. Due to the Chinese cultural values that place emphasis on harmony, as highlighted through the practices of showing respect for authority, conformity and Guanxi, it is essential that tourism workers understand the intricacies of the Chinese culture, thereby ensuring the smooth operation of the tours. It has been observed from the fieldtrips that tour guides make a concerted effort in ensuring that the leader of the group is assigned the best hotel room available to the group, the front seat on the coach, seeking the leader's approval in any decisions, the honourable seat at the dinning table and so forth. While this kind of practice was not an unusual for the tour guides who are Chinese descendents, other industry personnel from the hotels, theme parks and other destinations visited, were not aware of the cultural values and required a constant 'negotiation' through the tour guides. With a wider awareness of the Chinese cultural values from the industry practitioners, the 
service-negotiation point can be made wider, moving beyond usually a one-person point as the tour guide.

For academia, we suggest that there should be more attempts to try to understand non-Euro/ Western tourists, involving ethnographic type of methodology. This study has highlighted the importance of developing a deeper understanding on Chinese cultural values in tourism context. Current tourism research has focused largely on Western tourism development and as such, these theories and concepts may not be suitable for non-Euro/Western settings (The Chinese Culture Connection, 1987). As the core of Chinese culture, Confucianism is believed to influence the political and economic dynamics of Chinese societies as well as the personal, social and cultural dynamics of everyday life (Yeung \& Tung 1996; Fan, 2000). More research on one of the major Chinese cultural values, Confucianism in relation to tourists' behaviour, is a timely academic investment of today for advanced understanding of the culture and tourism.

\section{Conclusion}

In this paper, we have looked into the major Chinese cultural and philosophical value of Confucianism in relation to the behaviours of Chinese corporate tourists on the Gold Coast, Australia. The findings of this study suggest that even though the members of the tour groups were engaged in tourism activities, they continued to operate at the corporate organisational level. The experiences of the participants also illustrated how tourism activities has been utilised as a form of corporate recreation aimed at fostering a better work relationship among work colleagues and clients. Seen in this perspective, tourism 
can be seen as a venue/ tool that Mainland Chinese corporate travellers employ to establish and develop harmony.

While exploratory in nature in the context of tourism research, the empirical findings of this study confirm other disciplinary studies conducted in the fields of Chinese psychology, social psychology and organisational behaviour. Future research directed to better understand the socially constructing influence of Confucianism on Chinese tourists is highly recommended. Studies can investigate further into other Confucius values other than ' $\mathrm{Li}$ ', argued as the underlying philosophical and cultural grounds to put the utmost emphasis on harmony among the tourists in this paper. 


\section{References}

Baron, R. S., \& Kerr, N. L. (2003). Group Process, Group Decision, Group Action (2 ${ }^{\text {nd }}$ ed.). Guildford: Open University Press.

Bond, M. H., \& Hwang, K.-K. (1986). The Social Psychology of Chinese People. In M. H. Bond (Ed.), The Psychology of the Chinese People. Hong Kong: Oxford University Press.

Bowen, D. (2002). Research through participant observation in tourism: A creative solution to the measurement of consumer satisfaction/dissatisfaction (CS/D) among tourists. Journal of Travel Research, 41, 4-14.

Bowie, D., \& Chang, J. C. (2005). Tourist satisfaction: A view from a mixed international guided package tour. Journal of Vacation Marketing, 11(4), 303322.

Buttery, E. A., \& Wong, Y. H. (1999). The development of a guanxi framework. Marketing Intelligence \& Planning, 17(3), 147-154.

Cai, L. A., O'Leary, J. T., \& Boger, C. (1999). Chinese travellers to the United States: An emerging market. Journal of Vacation Marketing, 6(2), 131-144.

Chai, C., \& Chai, W. (Eds.). (1973). Confucianism. Woodbury: Barron's Educational Series.

Chan, H. L., Ko, A., \& Yu, E. (2000). Confucianism and management. In O. H. M. Yau \& H. C. Steele (Eds.), China Business: Challenges in the $21^{\text {st }}$ century (pp. 179192). Hong Kong: The Chinese University of Hong Kong.

Cohen, E. (1985). The tourist guide: The origins, structure and dynamics of a role. Annals of Tourism Research, 12, 5-29.

Creswell, J. W., \& Miller, D.L. (2000). Determining validity in qualitative inquiry. Theory into Practice, 39, 124-130.

Crompton, J. L. (1981). Dimensions of the social group role in pleasure vacations. Annals of Tourism Research, VIII(4), 550-568.

Davidson, R., Hertrich, S., \& Schwandner, G. (2004). How can Europe capture Chinese mice? Paper presented at the APTA Conference 2004, Globalisation and Tourism Research: East Meets West, Nagasaki, Japan. 
Fairley, S. (2003). In search of relived social experience: Group based nostalgia sport tourism. Journal of Sport Management, 17, 284-304.

Fan, Y. (2000). A classification of Chinese culture. Cross Cultural Management- An International Journal, 7(10), 3-10.

Gong, W. (2002). Chinese consumer behaviour: A cultural framework and implications. Journal of American Academy of Business, Cambridge, 3(1/2), 373-381.

Goffman, E. (1959). The presentation of self in everyday life. New York: Anchor Books. Gorman, B. (1979). Seven days, five countries: The making of a group. Urban Life, 7(4), 469-491.

Hofstede, G. (1980). Culture's Consequences: International Differences in Work Related Values. Beverly Hills, CA: Sage.

Hofstede, G., \& Hofstede, G. J. (2005). Cultures and organisations: Software of the mind. New York: McGraw-Hill.

Hogg, M. A. (1992). The Social Psychology of Group Cohesiveness: From Attraction to Social Identity. London: Harvester Wheatsheaf.

Holloway, J. C. (1981). The guided tour: A sociological approach. Annals of Tourism Research, VIII(3), 377-402.

Huang, S., \& Hsu, C. H. C. (2005). Mainland Chinese residents' perceptions and motivations of visiting Hong Kong: Evidence from focus group interviews. Asia Pacific Journal of Tourism Research, 10(2), 191-205.

Jacobs, J. B. (1979). A preliminary model of particularistic ties in Chinese political alliances: Kanching and kuan-hsi in a rural Taiwanese township. . China Quarterly, 78, 237-273.

Kau, A. K., \& Lim, P. S. (2005). Clustering of Chinese tourists to Singapore: An analysis of their motivations, values and satisfaction. International Journal of Tourism Research, 7, 231-248.

Leung, K., Koch, P. T., \& Lu, L. (2002). A dualistic model of harmony and its implications for conflict management in Asia. Asia Pacific Journal of Management, 19(2,3), 201.

Littrell, R. F. (2002). Desirable leadership behaviours of multi-cultural managers in China. Journal of Management Development, 21(1), 5-74. 
Lu, M. (1983). Confucianism: Its Relevance to Modern Society. Singapore: Federal Publications.

Luo, Y. (1997). Guanxi: Principles, philosophies, and implications. Human Systems Management, 16(1), 43.

Patton, M. Q. (2002). Qualitative research and evaluation methods (3rd ed.). California: Sage.

Peng, M. W. (1997). The importance of guanzi (connections) in China. In I. Chow, N. Holbert, L. Kelly \& J. Yu (Eds.), Business strategy: An Asia-Pacific focus. New York: Prentice Hall.

Qu, H., \& Li, I. (1997). The characteristics and satisfaction of Mainland Chinese visitors to Hong Kong. Journal of Travel Research, 35(4), 37-41.

Quiroga, I. (1990). Characteristics of package tours in Europe. Annals of Tourism Research, 17, 185-207.

Ryan, C., \& Mo, X. (2001). Chinese visitors to New Zealand- demographics and perceptions. Journal of Vacation Marketing, 8(1), 13-27.

Schmidt, C. J. (1979). The guided tour: Insulated adventure. Urban Life, 7(4), 441-467.

Schuchat, M. G. (1983). Comforts of group tours. Annals of Tourism Research, 10, 465477.

Silin, R. (1976). Leadership and values. Cambridge: Harvard University Press.

Szeto, R., \& Wright, P. C. (2006). Business networking in the Chinese context: Its role in the formation of guanxi, social capital and ethical foundations. Management Research News, 29(7), 425-438.

Winter, D. (1992). Motivation and personality: handbook of thematic content analysis. In C. P. Smith, J.W. Atkinson, D.C. McClelland \& J, Veroff (Ed.), Content analysis of archival materials, personal documents, and everyday verbal productions. Cambridge; New York: Cambridge University Press.

Tai, S. H. C., \& Tam, J. L. M. (1996). A comparative study of Chinese consumers in Asian markets: A lifestyle analysis. Journal of International Consumer Marketing, 9(1), 25-42.

Tamney, J. B., \& Chiang, L. H.-L. (2002). Modernisation, Globalisation, and Confucianism in Chinese Societies. Westport: Praeger Publishers. 
Tjosvold, D., Hui, C., \& Sun, H. (2004). Can Chinese discuss conflicts openly? Field and experimental studies of face dynamics in China. Group Decision and Negotiation, 13, 351-373.

Tucker, H. (2005). Narratives of place and self: Differing experiences of package coach tours in New Zealand. Tourist Studies, 5, 267-282.

Wang, K.-C., Hsieh, A.-T., \& Chen, W.-Y. (2002). Is the tour leader an effective endorser for group package tour brochures? Tourism Management, 23, 489-498.

Wang, K.-C., Hsieh, A.-T., Chou, S.-H., \& Lin, Y.-S. (2007). GPTCCC: An instrument for measuring group package tour service. Tourism Management, 28, 361-376.

Wang, K.-C., Hsieh, A.-T., \& Huan, T.-C. (2000). Critical service features in group package tour: An exploratory research. Tourism Management, 21, 177-189.

Warner, M., \& Zhu, Y. (2002). Human resource management "with Chinese characteristics": A comparative study of the People's Republic of China and Taiwan. Asia Pacific Business Review, 9(2), 21-43.

Wong, Y. H., \& Chan, R. Y.-K. (1999). Relationship marketing in China: Guanxi, favouritism and adaptation. Journal of Business Ethics, 22(107-118).

Wong, Y. H., \& Tam, J. L. M. (2000). Mapping relationships in China: Guanxi dynamic approach. Journal of Business \& Industrial Marketing, 15(1), 57-70.

Yao, X. Z. (2000). An Introduction to Confucianism. Cambridge: Cambridge University Press.

Yau, O. H. M. (1994). Consumer Behaviour in China: Customer Satisfaction and Cultural Values. Cornwall: Routledge.

Yau, O. H. M. (2000). Chinese Cultural Values: Their Dimensions and Marketing Implications. In O. H. M. Yau \& H. C. Steele (Eds.), China Business: Challenges in the $21^{\text {st }}$ Century (pp. 133-150). Hong Kong: The Chinese University of Hong Kong.

Yau, O. H. M., \& Steele, H. C. (Eds.). (2000). China Business: Challenges in the $21^{\text {st }}$ Century. Hong Kong: The Chinese University of Hong Kong.

Yeung, I. Y. M., \& Tung, R. L. (1996). Acheiving business success in Confucian societies: The importance of guanxi (connections). Organisational Dynamics, Autumn, 54-66. 
Yoo, J. J.-E., McKercher, B., \& Mena, M. (2004). A cross-cultural comparison of trip characteristics: International visitors to Hong Kong from Mainland Chian and USA. Journal of Travel \& Tourism Marketing, 16(1), 65-77.

Zhang, G., Pine, R., \& Zhang, Q. H. (2000). China's international tourism development: Present and future. International Journal of Contemporary Hospitality Management, 12(5), 282.

Zhang, H. Q., Chong, K., \& Ap, J. (1999). An analysis of tourism policy development in modern China. Tourism Management, 20, 471-485.

Zhang, Q. H., \& Heung, C. S. (2001). The emergence of Mainland Chinese outbound market and its implications. Journal of Vacation Marketing, 8(1), 7-12.

Zhang, Q. H., \& Lam, T. (1999). An analysis of Mainland Chinese visitors' motivations to visit Hong Kong. Tourism Management, 20, 587-594.

Zhang, Q. H., \& Qu, H. (1996). The trends of China outbound travel to Hong Kong and its implications. Journal of Vacation Marketing, 2(4), 373-381.

Zhang, W. (1999). Confucianism and Modernization: Industrialization and Democratization of the Confucian Regions. New York: St. Martin's Press. 